\title{
Validation of a Pulse Oximetry System for High-Altitude Waterfowl by Examining the Hypoxia Responses of the Andean Goose (Chloephaga melanoptera)
}

Catherine M. Ivy ${ }^{1 \dagger}$, Julia M. York ${ }^{2 \dagger}$, Sabine L. Lague ${ }^{2}$, Beverly A. Chua ${ }^{2}$, Luis Alza ${ }^{3,4}$, Kevin G. McCracken $^{3,4}$, William K. Milsom ${ }^{2}$, and Graham R. Scott ${ }^{1 *}$

${ }^{1}$ Department of Biology, McMaster University, Hamilton, ON, L8S 4K1, Canada

${ }^{2}$ Department of Zoology, University of British Columbia, Vancouver, BC, V6T 1Z4, Canada

${ }^{3}$ Department of Biology, Rosenstiel School of Marine and Atmospheric Sciences, and John P. Hussman Institute for Human Genomics, University of Miami, Coral Gables, FL, 33146, USA

${ }^{4}$ Centro de Ornitología y Biodiversidad (CORBIDI), Lima 33, Peru

${ }^{\dagger}$ Authors contributed equally

* Corresponding author; e-mail: scottg2@mcmaster.ca

Keywords: Andes, bird, duck, gas exchange, high-altitude adaptation, metabolism. 


\section{ABSTRACT}

3 Hypoxia at high altitudes constrains $\mathrm{O}_{2}$ supply to support metabolism, thermoregulation in the

4 cold, and exercise. High-altitude natives that somehow overcome this challenge - who live,

5 reproduce, and sometimes perform impressive feats of exercise at high altitudes - are a powerful

6 group in which to study the evolution of physiological systems underlying hypoxia resistance.

7 Here, we sought to determine whether a common pulse oximetry system for rodents (MouseOx

8 Plus ${ }^{\circledR}$ ) can be used reliably in studies of high-altitude birds, by examining the hypoxia responses

9 of the Andean goose. We compared concurrent measurements of heart rate obtained using pulse

10 oximetry versus electrocardiography (ECG). We also compared our measurements of peripheral

11 arterial $\mathrm{O}_{2}$ saturation $\left(\mathrm{SaO}_{2}\right)$ in uncannulated birds to published data collected from blood

12 samples in birds that were surgically implanted arterial cannulae. Responses to acute hypoxia

13 were measured during step-wise reductions in inspired partial pressure of $\mathrm{O}_{2}$. Andean geese

14 exhibited very modest breathing and heart rate responses to hypoxia, but were nevertheless able

15 to maintain normal $\mathrm{O}_{2}$ consumption rates during severe hypoxia exposure down to $5 \mathrm{kPa}_{2}$.

16 There were some minor quantitative differences between uncannulated and cannulated birds,

17 which suggested that surgery, cannulation, and/or other sources of variability between studies

18 had modest effects on the hypoxic ventilatory response, heart rate, blood haemoglobin, and

19 haematocrit. Nevertheless, measurements of heart rate and $\mathrm{SaO}_{2}$ by pulse oximetry had small

20 standard errors, and were generally concordant and well correlated with measurements using

21 other techniques. We conclude that the MouseOx Plus ${ }^{\circledR}$ pulse oximetry system can be a valuable

22 tool for studying the cardiorespiratory physiology of waterfowl without the deleterious effects of

23 surgery/cannulation. 


\section{Introduction}

2

High-altitude environments provide fertile ground to understand how the physiological systems of animals evolve. High-altitude environments are both cold and hypoxic, which can require that endotherms sustain high rates of $\mathrm{O}_{2}$ consumption for thermogenesis and locomotion while facing a diminished $\mathrm{O}_{2}$ supply. And yet, some birds can overcome this challenge, and can live, reproduce, and perform impressive feats of flight exercise at high altitudes (Herzog et al. 2005; Hawkes et al. 2013; Natarajan et al. 2016). The current evidence suggests that birds overcome the challenges at high altitude by virtue of evolved changes across the $\mathrm{O}_{2}$ transport cascade - comprised of ventilation, pulmonary diffusion, circulation, tissue diffusion, and cellular $\mathrm{O}_{2}$ utilization (Faraci 1991; Butler 2010; Scott 2011; Scott et al. 2015). However, with some exceptions (Storz 2016), many aspects of the physiology of high-altitude birds have been studied in only a few species.

Waterfowl (order Anseriformes) native to high altitudes are a powerful taxonomic group in which to study convergent evolution and phenotypic plasticity inherent in complex physiological systems such as the $\mathrm{O}_{2}$ cascade. Many species of ducks and geese have independently colonized similar high-altitude environments (McCracken et al. 2009; Natarajan et al. 2015), and some are known to fly at extremely high altitudes during their migration (Hawkes et al. 2013; Parr et al. 2017). The relatively large size of most waterfowl facilitates the use of many cardiorespiratory and bio-logging approaches that are difficult in smaller organisms (Black and Tenney 1980; Hawkes et al. 2014; Bishop et al. 2015; Guillemette et al. 2016). Previous work has shown that many high-altitude waterfowl have evolved a high blood- $\mathrm{O}_{2}$ affinity (Storz 2016), and two species in particular - bar-headed goose (Anser indicus) and Andean goose (Chloephaga melanoptera) - are renowned high-altitude natives that were the subject of classic early studies on molecular adaptation of haemoglobin (Jessen et al. 1991; Golding and Dean 1998; Scott et al. 2015). However, the extent to which haemoglobin adaptations augment arterial $\mathrm{O}_{2}$ saturation $\left(\mathrm{SaO}_{2}\right)$ in vivo, and whether other respiratory traits exhibit the same degree of convergent evolution at high altitudes, is not yet well understood.

The objective of this study was to examine whether a common pulse oximetry system used with rodents - the MouseOx Plus ${ }^{\circledR}$ from Starr Life Sciences (Oakmont, PA, USA) - can be used reliably to measure $\mathrm{SaO}_{2}$ in studies of waterfowl. This system, like all pulse oximeters, 
1 works based on the principle that oxyhemoglobin and deoxyhemoglobin have different

2 absorption properties for red and near-infrared light; when light of particular wavelengths are

3 passed into a tissue, the pulsatile fluctuations in absorbance during the cardiac cycle can be

4 measured to determine $\mathrm{SaO}_{2}$ (Chan et al. 2013). The reliability of the system depends upon the

5 site of measurement on the animal, the adequacy of perfusion, the absence of venous pulsations,

6 the absorption spectra of oxy- and deoxy-hemoglobin, and various other factors that can arise in

7 clinical situations (Chan et al. 2013). The MouseOx Plus ${ }^{\circledR}$ has been used in a variety of mammal

8 species, but it has never been validated for use in birds. Nevertheless, such a pulse oximetry

9 system would be extremely valuable for carrying out experiments on large numbers of

10 individuals (a necessity for examining the prevalence of convergent evolution across many high-

11 altitude taxa) and/or in the field, because it would facilitate measurements of peripheral $\mathrm{SaO}_{2}$

12 (along with heart rate) without needing to surgically implant birds with catheters for sampling

13 blood. Our general approach was to examine the hypoxia responses of Andean geese, comparing

14 the heart rate and $\mathrm{SaO}_{2}$ data collected with the MouseOx Plus ${ }^{\circledR}$ to heart rate measurements

15 collected using electrocardiography (ECG) and to previously published data on arterial

16 oxygenation that we measured in blood samples from cannulated birds (Lague et al. 2017). We

17 also measured various other cardiorespiratory variables to determine the extent to which surgery

18 and/or cannulation impacts breathing and respiratory gas exchange, and could thus alter

19 measurements of arterial oxygenation.

\section{Methods}

Study Animals

Adult Andean geese (Chloephaga melanoptera) were wild-caught in the Andes ( 4000$4500 \mathrm{~m}$ above sea level) and held in captivity for at least 6 months in San Pedro de Casta, Peru

$27(\sim 3,200 \mathrm{~m})$ before experiments were conducted. Birds were held in enclosures with a caged outdoor area that was connected to an indoor shelter through a small door. Birds were provided with free access to clean water and were fed a mix of local grains, commercially obtained

30 chicken feed, and alfalfa. Experiments using pulse oximetry were carried out on 7 uncannulated

31 Andean geese $(2.36 \pm 0.16 \mathrm{~kg})$ in August 2015, and were compared to a previously published 
data set from 7 cannulated Andean geese $(2.13 \pm 0.12 \mathrm{~kg})$ that was collected in May 2013 at the same location (Lague et al. 2017). In the latter study, birds underwent surgery one day before the experiment, in which the brachial artery and vein were cannulated under general isoflurane anaesthesia (see (Lague et al. 2017) for other details on the surgery). All procedures were carried out in accordance with guidelines set out by the Canadian Council on Animal Care, and were approved by institutional animal care committees.

\section{Measurement of Hypoxia Responses}

The ventilatory, cardiovascular, and metabolic responses to hypoxia were measured on uncannulated Andean geese wearing MouseOx Plus® pulse oximetry neck collars, using the same protocol that was used previously on cannulated Andean geese (Lague et al. 2017). It was preferable to place the pulse oximetry sensor on the neck, because hypoxia could foreseeably disrupt the signal if it reduced local blood flow (Shah et al. 2012), and this effect is likely much smaller in the neck than in many peripheral tissues (e.g., feet, wings, etc.). Birds were placed in a flexible cradle with their head in a 41 opaque chamber that was sealed around the neck using a latex collar, and were fitted with pulse oximetry collars as well as thin ECG electrodes (F-E2-12, Grass Technologies, Natus Medical Incorporated, Pleasanton, CA, USA) inserted under the skin on the back (except for one of the seven birds that was not instrumented with ECG electrodes, and only the pulse oximetry collar). Birds were then allowed 60-90 min to become accustomed to the experimental apparatus, with ambient air (which had an $\mathrm{O}_{2}$ tension, $\mathrm{PO}_{2}$, of $\sim 13.4 \mathrm{kPa}$ ) delivered to the opaque head chamber at a flow rate of $51 \mathrm{~min}^{-1}$. Measurements then began in ambient air for $25 \mathrm{~min}$, after which birds were exposed to 25 min step-wise decreases in the $\mathrm{PO}_{2}$ of air flowing into the head chamber $(12,9,7$, and $5 \mathrm{kPa})$, and then finally returned to breathing ambient air to recover for $25 \mathrm{~min}$. The $\mathrm{PO}_{2}$ of inflowing air was set by mixing air and nitrogen gas using pre-calibrated rotameters (Matheson Tri-Gas, Oakville, ON, Canada) at a flow rate of 5-10 $1 \mathrm{~min}^{-1}$. Use of the collars required that a small area of skin on the neck be plucked free of feathers, which was done at least $1 \mathrm{~h}$ before experiments began. A blood sample was collected using a lancet at the end of the experiment to measure blood haemoglobin content $([\mathrm{Hb}]$, using a

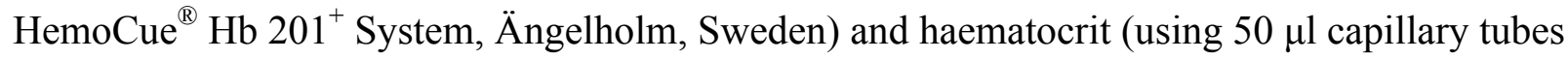
and a ZIPocrit centrifuge, LW Scientific, Lawrenceville, GA, USA). 
Various measurements were made from $\sim 13-15$ min of exposure at each inspired $\mathrm{PO}_{2}$

2 step, in order to be consistent with our previous measurements in cannulated Andean geese

3 (Lague et al. 2017). A pneumotachograph (8311A, Hans Rudolph, Shawnee, KS, USA) and

4 differential pressure transducer (DP45, Validyne, Northridge, CA, USA) were used to measure

5 excurrent flow rate from the head chamber $\left(\mathrm{FR}_{\mathrm{E}}\right)$, such that breathing-induced flows could be measured from deviations in the biased flow through the chamber. $\mathrm{O}_{2}$ fraction was measured in the air flowing into the head chamber $\left(\mathrm{F}_{\mathrm{I}} \mathrm{O}_{2}\right)$ during the first 5 min of exposure to each $\mathrm{PO}_{2}$, and $\mathrm{O}_{2}$ and $\mathrm{CO}_{2}$ fractions were then measured in the air leaving the head chamber $\left(\mathrm{F}_{\mathrm{E}} \mathrm{O}_{2}\right.$ and $\mathrm{F}_{\mathrm{E}} \mathrm{CO}_{2}$, respectively) from $\sim 13-15$ min at each $\mathrm{PO}_{2}$. To do so, air was subsampled at $\sim 200 \mathrm{ml} \mathrm{min}{ }^{-1}$, dried using silica gel, and then measured using a FMS Field Metabolic System (Sable Systems

11 International, Las Vegas, $\mathrm{NV}$, USA). Tidal volume $\left(\mathrm{V}_{\mathrm{T}}\right)$, breathing frequency $\left(\mathrm{f}_{\mathrm{R}}\right)$, and total 12 ventilation $\left(\dot{\mathrm{V}}_{\text {Tot }}\right.$; the product of $\mathrm{V}_{\mathrm{T}}$ and $\mathrm{f}_{\mathrm{R}}$ ) were determined as previously described (Lague et al. 2017). $\mathrm{O}_{2}$ consumption rate $\left(\mathrm{V}_{2}\right)$ was calculated using the following well-established equation (Lighton 2008):

$$
\dot{\mathrm{VO}_{2}}=\mathrm{FR}_{\mathrm{E}} \frac{\mathrm{F}_{\mathrm{I}} \mathrm{O}_{2}-\mathrm{F}_{\mathrm{E}} \mathrm{O}_{2}-\mathrm{F}_{\mathrm{I}} \mathrm{O}_{2} \times \mathrm{F}_{\mathrm{E}} \mathrm{CO}_{2}}{1-\mathrm{F}_{\mathrm{I}} \mathrm{O}_{2}}
$$
However, $\mathrm{F}_{\mathrm{E}} \mathrm{CO}_{2}$ was not measured for technical reasons in the previous study of cannulated

16 Andean geese (Lague et al. 2017), such that $\mathrm{V}_{2}$ was approximated using the equation

$17 \quad \dot{\mathrm{VO}}_{2}=\mathrm{FR}_{\mathrm{E}}\left[\mathrm{F}_{\mathrm{I}} \mathrm{O}_{2}-\mathrm{F}_{\mathrm{E}} \mathrm{O}_{2}\right]$. Therefore, for the uncannulated geese in the current study, we also

18 calculated $\mathrm{VO}_{2}$ using this approximation and used it to determine the ventilatory equivalent

19 (quotient of $\dot{\mathrm{V}}_{\mathrm{Tot}}$ and $\dot{\mathrm{V}} \mathrm{O}_{2}$ ), in order to compare with data collected from cannulated geese in the 20 previous study. $\dot{\mathrm{VO}}_{2}$ and ventilatory equivalents calculated using the approximation are reported 21 in fig. 1, but we also report results from the correct calculation of $\mathrm{VO}_{2}$ in the text of the results. 22 Heart rate was determined from the frequency of QRS complexes in the ECG signal. These data 23 were acquired and analyzed using PowerLab data acquisition hardware and LabChart Pro 24 software (ADInstruments, Colorado Springs, CO, USA). Heart rate and arterial $\mathrm{O}_{2}$ saturation $25\left(\mathrm{SaO}_{2}\right)$ were also measured with the pulse oximetry collars using the MouseOx Plus ${ }^{\circledR}$ software. 
We sought to validate our measurements of peripheral $\mathrm{SaO}_{2}$ using pulse oximetry by comparing them to $\mathrm{SaO}_{2}$ values for cannulated Andean geese, calculated from our previous direct measurements (Lague et al. 2017) of arterial $\mathrm{O}_{2}$ content $\left(\mathrm{CaO}_{2}\right.$, in $\mathrm{ml} \mathrm{O}_{2}$ per dl blood) using the Tucker method (Tucker 1967), arterial $\mathrm{PO}_{2}\left(\mathrm{PaO}_{2}\right.$, in Torr) using an i-STAT blood gas analyzer (Harter et al. 2015), and [Hb] (in g per dl blood) using the following equation (Grocott et al. 2009):

$$
\mathrm{SaO}_{2}=\frac{\mathrm{CaO}_{2}-0.003 \mathrm{PaO}_{2}}{1.39[\mathrm{Hb}]}
$$

Data are generally reported as means \pm s.e.m. unless stated otherwise. Two-factor ANOVA followed by Bonferroni post-tests or unpaired t-tests were used as appropriate to evaluate the main effects of inspired $\mathrm{PO}_{2}$ or to compare between the data collected here in uncannulated Andean geese and that collected previously in cannulated Andean geese. Linear regression was also used to examine the relationship between the $\mathrm{SaO}_{2}$ or heart rate data collected using different techniques. Statistics were performed using GraphPad Prism software (La Jolla, CA). A significance level of $p<0.05$ was used throughout.

\section{Results}

Hypoxia Responses of Andean Geese

Andean geese exhibited relatively modest responses to acute hypoxia exposure, some of which differed between cannulated and uncannulated birds (fig. 1). Total ventilation increased in response to acute hypoxia (main effect of inspired $\mathrm{PO}_{2}$ in two-factor ANOVA: $\mathrm{F}_{4,56}=14.6$, $\mathrm{P}<0.001)$, driven by increases in both breathing frequency $\left(\mathrm{F}_{4,56}=4.95, \mathrm{P}=0.002\right)$ and tidal volume $\left(\mathrm{F}_{4,56}=6.31, \mathrm{P}<0.001\right)$. However, the magnitude of the increases in total ventilation was greater in uncannulated than in cannulated birds (main effect of cannulation in two-factor ANOVA: $\mathrm{F}_{1,56}=26.2, \mathrm{P}<0.001$ ), increasing $76 \%$ versus $35 \%$ at $5 \mathrm{kPa}$ compared to ambient air, and this difference arose largely from differences in tidal volume $\left(\mathrm{F}_{1,56}=18.2, \mathrm{P}<0.001\right)$ and not breathing frequency $\left(\mathrm{F}_{1,56}=1.64, \mathrm{P}=0.205\right)$. Cannulated and uncannulated birds had similar $\mathrm{O}_{2}$ consumption rates $\left(\mathrm{F}_{1,53}=0.781, \mathrm{P}=0.381\right)$, which were maintained in response to acute hypoxia in both groups $\left(\mathrm{F}_{4,53}=0.551, \mathrm{P}=0.767\right)$. Therefore, the pattern of variation in ventilatory 
1 equivalent for $\mathrm{O}_{2}$ (the quotient of total ventilation and $\mathrm{O}_{2}$ consumption rate; also called the air

2 convection requirement) was similar to the variation in total ventilation, with increases in response to acute hypoxia $\left(\mathrm{F}_{4,51}=5.86, \mathrm{P}<0.001\right)$ that were greater in magnitude in the uncannulated birds $\left(\mathrm{F}_{1,51}=20.9, \mathrm{P}<0.001\right)$. It is important to note that the $\mathrm{O}_{2}$ consumption rates in fig. 1 were calculated using a simplified equation that overestimated the true values by $\sim 3-5 \%$ (see Methods for explanation), but are reported in this way in order to compare with the data for cannulated birds from our previous study of Andean geese (Lague et al. 2017). The correctly calculated values for uncannulated birds were extremely similar and did not change in response to hypoxia $\left(\dot{\mathrm{VO}}_{2}\right.$ in $\mathrm{ml} / \mathrm{kg} / \mathrm{min}$ at each inspired $\mathrm{PO}_{2}: 13.4 \mathrm{kPa}, 11.5 \pm 1.5 ; 12 \mathrm{kPa}, 11.6 \pm 1.6 ; 9$ $\mathrm{kPa}, 10.9 \pm 1.3 ; 7 \mathrm{kPa}, 10.6 \pm 1.6 ; 5 \mathrm{kPa}, 10.3 \pm 1.3)$. Nevertheless, the above results suggest that there were some small differences in breathing between cannulated and uncannulated birds that may have led to differences in respiratory gas exchange.

There were also some differences in cardiovascular variables between cannulated and uncannulated Andean geese. Heart rate increased in both groups with exposure to deep hypoxia $\left(\mathrm{F}_{4,54}=5.23, \mathrm{P}=0.001\right)$, but the magnitude was slightly greater in cannulated birds (in which heart rate was measured from arterial catheters as the frequency of systolic pressure peaks; Lague et al. 2017) than in uncannulated birds (in which heart rate was measured by $E C G)\left(F_{1,54}=5.48\right.$, $\mathrm{P}=0.023$ ) (fig. 1). Blood haemoglobin content ([Hb]) and haematocrit were also lower in cannulated geese (table 1).

Validation of the MouseOx Plus Pulse Oximetry System and those collected using the MouseOx Plus ${ }^{\circledR}$ pulse oximetry system, both of which were made in the uncannulated birds studied here (fig. 2). There was a strong linear regression between data collected by pulse oximetry and by ECG in individual uncannulated birds $(\mathrm{y}=0.913 \mathrm{x}+12.37$; $\left.\mathrm{R}^{2}=0.902 ; \mathrm{P}<0.001\right)$, and this regression was statistically indistinguishable from the line of equality. Therefore, the pulse oximetry system appeared to provide accurate measurements of heart rate, such that the differences in heart rate between uncannulated and cannulated Andean geese (fig. 1) were likely attributable to the effects of surgery, cannulation, or some other source of variation between the birds studied here and those in our previous study (Lague et al. 2017). 
The measurements of arterial $\mathrm{O}_{2}$ saturation $\left(\mathrm{SaO}_{2}\right)$ were slightly higher in the uncannulated Andean geese using the MouseOx Plus ${ }^{\circledR}$ pulse oximetry system than in the cannulated Andean geese, in which $\mathrm{SaO}_{2}$ was calculated from previous measurements of arterial $\mathrm{O}_{2}$ content, arterial $\mathrm{PO}_{2}$, and $[\mathrm{Hb}]$ from blood samples $\left(\mathrm{F}_{1,52}=13.9, \mathrm{P}<0.001\right.$ in two-factor ANOVA) (Lague et al. 2017) (fig. 3). $\mathrm{SaO}_{2}$ declined in response to acute hypoxia in both groups $\left(\mathrm{F}_{4,52}=59.6, \mathrm{P}<0.001\right.$ in two-factor ANOVA). Despite the differences in $\mathrm{SaO}_{2}$ between groups, which was greatest at an inspired $\mathrm{PO}_{2}$ of $7 \mathrm{kPa}$ and could have arisen from differences in respiratory gas exchange between groups, there was a strong linear regression between $\mathrm{SaO}_{2}$ data measured here in uncannulated birds and the data measured previously (Lague et al. 2017) in cannulated birds $\left(\mathrm{y}=0.917 \mathrm{x}+14.3 ; \mathrm{R}^{2}=0.965 ; \mathrm{P}=0.003\right)$ (fig. 3B). It is also worth noting that the standard errors of the $\mathrm{SaO} 2$ measurements using pulse oximetry in uncannulated birds were generally similar or less than those obtained from blood samples in cannulated birds.

\section{Discussion}

High-altitude waterfowl are valuable model organisms for studying the evolution of the $\mathrm{O}_{2}$ transport cascade. Here, we evaluate whether a common pulse oximetry system developed for rodents can be used to study the cardiorespiratory mechanisms of high-altitude adaptation in waterfowl. The system was able to accurately measure the heart rate response to hypoxia across a range of inspired $\mathrm{O}_{2}$ tensions (fig. 2), and there was a strong and predictable relationship between the arterial $\mathrm{O}_{2}$ saturations measured with the system and those determined from blood samples in previous studies (Lague et al. 2017) (fig. 3B). Pulse oximetry can therefore be used as a valuable tool for examining the cardiorespiratory mechanisms of high-altitude adaptation in waterfowl and other birds.

The MouseOx Plus Pulse Oximetry System is a Valuable Tool for Studying Cardiorespiratory Physiology of Waterfowl

Arterial $\mathrm{O}_{2}$ saturation measurements with the pulse oximetry system were higher than those determined from blood samples in previous studies (Lague et al. 2017) (fig. 3), but this distinction was likely influenced by the effects of surgery, cannulation, or other sources of 
1 between-study variability on breathing and respiratory gas exchange. The uncannulated birds used for pulse oximetry took deeper breaths and had higher total ventilation than cannulated birds, particularly during exposure to more severe levels of hypoxia (fig. 1), and these differences would be expected to raise $\mathrm{SaO}_{2}$ by increasing arterial $\mathrm{O}_{2}$ tension (Ivy and Scott 2015). The higher total ventilation in uncannulated birds may have also accentuated the magnitude of respiratory hypocapnia that was experienced during exposure to acute hypoxia, which would be expected to left-shift the haemoglobin- $\mathrm{O}_{2}$ equilibirum curve and further increase $8 \mathrm{SaO}_{2}$ (Scott and Milsom 2007, 2009). These differences between cannulated and uncannulated birds are perhaps unsurprising, insofar as surgery and cannulation are known to have persistent effects on cardiorespiratory function (Duthie and Tort 1985; Van Vliet et al. 2006). It is also

11 possible that annual or seasonal variation contributed to some of the observed differences

12 between cannulated and uncannulated birds, because experiments were conducted on 13 uncannulated birds in August 2015 and on cannulated birds in May 2013. However, there have 14 been very few studies on the effects of seasonal variation or chronic temperature acclimation on 15 breathing and respiratory gas exchange in birds (Swanson 2010), and some evidence suggests 16 that total ventilation remains well matched to metabolism and that ventilatory equivalent does 17 not change between summer and winter (Arens and Cooper 2005). If this was also true in Andean geese during hypoxia exposure, then seasonal variation cannot account for the observed differences between cannulated and uncannulated birds. Regardless of the source of variation, the strong relationship between methods and across studies $\left(R^{2}=0.965\right.$; fig. $\left.3 B\right)$ suggests that the differences between $\mathrm{SaO}_{2}$ data measured in uncannulated birds using pulse oximetry and in cannulated birds in blood samples are predictable and can be corrected for.

The measurements of heart rate using the pulse oximetry system were strongly correlated with the concurrent measurements using ECG (fig. 2). It is therefore likely that the differences in heart rate responses to hypoxia between groups of Andean geese (fig. 1) could be attributed to effects of surgery, cannulation, or other differences between studies, possibly in association with the modest decreases in blood haemoglobin concentration $([\mathrm{Hb}])$ and haematocrit in cannulated birds (table 1). Therefore, although cannulation is a valuable method for some important cardiovascular measurements (e.g., blood pressure, contents and partial pressures of $\mathrm{O}_{2}$ and $\mathrm{CO}_{2}$, $30 \mathrm{pH}$, etc.), we believe that pulse oximetry is preferable to more invasive methods for measuring 
$\mathrm{SaO}_{2}$ and heart rate because it is simpler to use and it avoids the effects of surgery and/or cannulation on breathing and haematology.

Can the MouseOx Plus ${ }^{\circledR}$ pulse oximetry system be used in other species of birds? Our results suggest that the neck is an adequate site of measurement that receives sufficient perfusion in hypoxia to provide a reliable signal for pulse oximetry, and this finding should be generally applicable across waterfowl and other bird species. The absorption spectra of oxy- and deoxyhemoglobin could differ between species, and this could in theory influence pulse oximetry measurements (Chan et al. 2013). For example, some inherited forms of abnormal hemoglobin in humans can alter absorption spectra such that $\mathrm{SaO}_{2}$ measurements are abnormally low (Zur et al. 2008; Chan et al. 2013). However, the spectral properties of normal hemoglobin are known to be very similar and pulse oximetry can be used reliably across humans and several other mammals species (Grosenbaugh et al. 1997). Therefore, although some caution should be exercised in using pulse oximetry across species, particularly in those for which haemoglobin absorption spectra have not been characterized, the MouseOx Plus ${ }^{\circledR}$ will likely provide a valuable tool for comparing the physiology of closely related taxa from different environments.

\section{Andean Geese Have Blunted Ventilatory Responses to Acute Hypoxia}

We confirm our recent finding that Andean geese exhibit a ventilatory response to hypoxia that is dramatically blunted compared to other species (Lague et al. 2017). Despite the effects of surgery and cannulation on breathing (fig. 1), the hypoxic ventilatory response (HVR) of Andean geese is still markedly attenuated in comparison to many other species of birds (Black and Tenney 1980; Kilgore et al. 2007; Scott and Milsom 2009). This is well illustrated by the appreciably smaller HVR in Andean geese compared to that in low-altitude greylag geese (Anser anser) and Pekin ducks (Anas platyrhynchos) (fig. 4) (Scott and Milsom 2007). It is possible that the blunted HVR of Andean geese arose from environmentally-induced plasticity (e.g., developmental plasticity, adult acclimatization), because the birds studied here were sourced as juveniles from nearby elevations $(\geq 4,000 \mathrm{~m}$ ) and were raised and studied at 3,200 $\mathrm{m}$. However, previous studies show equivocal support for this possibility, as exposure to chronic hypoxia has more often (though not always) been observed to augment the HVR of waterfowl (Black and 
Tenney 1980; Powell et al. 2004; Lague et al. 2016). The blunted HVR of Andean geese has more likely evolved over evolutionary time periods as an adaptation to high altitudes.

What is the potential advantage of a blunted HVR in Andean geese? This result is somewhat surprising because it could be counterproductive to $\mathrm{O}_{2}$ transport in hypoxia. It has been suggested that a blunting of the HVR could be beneficial at high altitudes for maintaining blood $\mathrm{CO}_{2} / \mathrm{pH}$ homeostasis (by minimizing respiratory hypocapnia), attenuating respiratory water loss, or reducing the metabolic cost of breathing (Powell 2007). The blunting of the HVR could also be a secondary consequence of an overall attenuation of the hypoxic chemoreflex to avoid chronic activation of the sympathetic nervous system at high altitudes (Ivy and Scott 2017). However, Andean geese appear to have a very large lung with exceptional morphological capacity for $\mathrm{O}_{2}$ diffusion (Maina et al. 2017), which could obviate the need for a robust HVR and allow this species to take advantage of the benefits of breathing less.

The blunted HVR exhibited by Andean geese has also evolved in some high-altitude taxa, but is very different to the evolutionary path taken by some other taxa. For example, the barheaded goose - a species that flies at high altitudes during its migration across the Himalayas has a pronounced HVR in comparison to low-altitude waterfowl (fig. 4) (Scott and Milsom 2007). This distinction between Andean geese and bar-headed geese is surprisingly similar to that between high-altitude human populations from South America and Asia: Andean humans have a blunted HVR whereas Tibetans have an enhanced HVR compared to their lowland counterparts (Wu and Kayser 2006; Brutsaert 2016). The reason for this intriguing result is unclear, but it suggests that the selective advantage of the hypoxia response may differ between lineages or between distinct high-altitude regions. Future studies aimed at exploring these possibilities in waterfowl, for which there are many species that have independently colonized similar high-altitude environments (McCracken et al. 2009; Natarajan et al. 2015), will be greatly facilitated by the use pulse oximetry to understand how patterns of variation in the HVR impact respiratory $\mathrm{O}_{2}$ uptake.

\section{Acknowledgements}

The authors would like to thank Michelle Reichert as well as Emil Bautista and his family in San Pedro de Casta, Lima, Peru. This research was supported by Natural Sciences and Engineering Research Council of Canada (NSERC) Discovery Grants to G.R.S. and W.K.M., an Early 
1 Researcher Award from the Ontario Ministry of Research and Innovation to G.R.S., a National 2 Science Foundation grant (IOS-0949439) and the James A. Kushlan Endowment for Waterbird

3 Biology and Conservation at the University of Miami to K.G.M, and NSERC Graduate

4 Scholarships to C.M.I. and S.L.L. G.R.S. is supported by the Canada Research Chairs Program. 5

\section{Literature Cited}

7

Arens J.R. and S.J. Cooper. 2005. Seasonal and diurnal variation in metabolism and ventilation in house sparrows. Condor 107:433-444.

Bishop C.M., R.J. Spivey, L.A. Hawkes, N. Batbayar, B. Chua, P.B. Frappell, W.K. Milsom, T. Natsagdorj, S.H. Newman, G.R. Scott, J.Y. Takekawa, M. Wikelski, and P.J. Butler. 2015. The roller coaster flight strategy of bar-headed geese conserves energy during Himalayan migrations. Science 347:250-254.

Black C.P. and S.M. Tenney. 1980. Oxygen transport during progressive hypoxia in high altitude and sea level waterfowl. Respir Physiol 39:217-239.

Brutsaert T. 2016. Why are high altitude natives so strong at high altitude? Nature vs. nurture: genetic factors vs. growth and development. Adv Exp Med Biol 903:101-112.

Butler P.J. 2010. High fliers: the physiology of bar-headed geese. Comp Biochem Physiol A Mol Integr Physiol 156:325-329.

Chan E.D., M.M. Chan, and M.M. Chan. 2013. Pulse oximetry: understanding its basic principles facilitates appreciation of its limitations. Respir Med 107:789-799.

Duthie G.G. and L. Tort. 1985. Effects of dorsal aortic cannulation on the respiration and haematology of mediterranean living Scyliorhinus canicula L. Comp Biochem Physiol A 81:879-883.

Faraci F.M. 1991. Adaptations to hypoxia in birds: how to fly high. Annu Rev Physiol 53:59-70. 
1 Golding G.B. and A.M. Dean. 1998. The structural basis of molecular adaptation. Mol Biol Evol 15:355-369.

Grocott M.P.W., D.S. Martin, D.Z.H. Levett, R. McMorrow, J. Windsor, and H.E. Montgomery. 2009. Arterial blood gases and oxygen content in climbers on Mount Everest. N Engl J Med 360:140-149.

Grosenbaugh D.A., J.O. Alben, and W.W. Muir. 1997. Absorbance spectra of inter-species hemoglobins in the visible and near infrared regions. J Vet Emerg Crit Care 7:36-42.

Guillemette M., A.J. Woakes, J. Larochelle, E.T. Polymeropoulos, J.M. Granbois, P.J. Butler, D. Pelletier, P.B. Frappell, and S.J. Portugal. 2016. Does hyperthermia constrain flight duration in a short-distance migrant? Philos Trans R Soc Lond B Biol Sci 371:20150386.

Harter T.S., M. Reichert, C.J. Brauner, and W.K. Milsom. 2015. Validation of the i-STAT and HemoCue systems for the analysis of blood parameters in the bar-headed goose, Anser indicus. Conserv Physiol 3:cov021.

Hawkes L.A., S. Balachandran, N. Batbayar, P.J. Butler, B. Chua, D.C. Douglas, P.B. Frappell, Y. Hou, W.K. Milsom, S.H. Newman, D.J. Prosser, P. Sathiyaselvam, G.R. Scott, J.Y. Takekawa, T. Natsagdorj, M. Wikelski, M.J. Witt, B. Yan, and C.M. Bishop. 2013. The paradox of extreme high-altitude migration in bar-headed geese Anser indicus. Proc R Soc B 280:20122114.

Hawkes L.A., P.J. Butler, P.B. Frappell, J.U. Meir, W.K. Milsom, G.R. Scott, and C.M. Bishop. 2014. Maximum running speed of captive bar-headed geese is unaffected by severe hypoxia. PLoS One 9:e94015. 
1 Herzog S.K., M. Kessler, and K. Bach. 2005. The elevational gradient in Andean bird species richness at the local scale: a foothill peak and a high-elevation plateau. Ecography 28:209-222.

Ivy C.M. and G.R. Scott. 2015. Control of breathing and the circulation in high-altitude mammals and birds. Comp Biochem Physiol A Mol Integr Physiol 186:66-74.

Ivy C.M. and G.R. Scott. 2017. Control of breathing and ventilatory acclimatization to hypoxia in deer mice native to high altitudes. Acta Physiol In press.

Jessen T.-H., R.E. Weber, G. Fermi, J. Tame, and G. Braunitzer. 1991. Adaptation of bird hemoglobins to high altitudes: demonstration of molecular mechanism by protein engineering. Proc Natl Acad Sci U S A 88:6519-6522.

Kilgore D.L., D.F. Boggs, T.J. Kilgore, C. Colby, B.R. Williams, and R.W. Bavis. 2007. Ventilatory and metabolic responses of burrowing owls, Athene cunicularia, to moderate and extreme hypoxia: Analysis of the hypoxic ventilatory threshold vs. hemoglobin oxygen affinity relationship in birds. Comp Biochem Physiol A 150:247-257.

Lague S.L., B. Chua, L. Alza, G.R. Scott, P.B. Frappell, Y. Zhong, A.P. Farrell, K.G. McCracken, Y. Wang, and W.K. Milsom. 2017. Divergent respiratory and cardiovascular responses to hypoxia in bar-headed geese and Andean birds. J Exp Biol Accepted.

Lague S.L., B. Chua, A.P. Farrell, Y. Wang, and W.K. Milsom. 2016. Altitude matters: differences in cardiovascular and respiratory responses to hypoxia in bar-headed geese reared at high and low altitudes. J Exp Biol 219:1974-1984.

Lighton J.R.B. 2008. Measuring metabolic rates: a manual for scientists. Oxford University Press, USA. 
Maina J.N., K.G. McCracken, B. Chua, J.M. York, and W.K. Milsom. 2017. Morphological and morphometric specializations of the lung of the Andean goose, Chloephaga melanoptera: a lifelong high-altitude resident. PLoS One 12:e0174395.

McCracken K.G., C.P. Barger, M. Bulgarella, K.P. Johnson, S.A. Sonsthagen, J. Trucco, T.H. Valqui, R.E. Wilson, K. Winker, and M.D. Sorenson. 2009. Parallel evolution in the major haemoglobin genes of eight species of Andean waterfowl. Mol Ecol 18:3992-4005.

Natarajan C., F.G. Hoffmann, R.E. Weber, A. Fago, C.C. Witt, and J.F. Storz. 2016. Predictable convergence in hemoglobin function has unpredictable molecular underpinnings. Science 354:336-339.

Natarajan C., J. Projecto-Garcia, H. Moriyama, R.E. Weber, V. Munoz-Fuentes, A.J. Green, C. Kopuchian, P.L. Tubaro, L. Alza, M. Bulgarella, M.M. Smith, R.E. Wilson, A. Fago, K.G. McCracken, and J.F. Storz. 2015. Convergent evolution of hemoglobin function in high-altitude Andean waterfowl involves limited parallelism at the molecular sequence level. PLoS Genet 11:e1005681.

Parr N., S. Bearhop, D.C. Douglas, J.Y. Takekawa, D.J. Prosser, S.H. Newman, W.M. Perry, S. Balachandran, M.J. Witt, Y. Hou, Z. Luo, and L.A. Hawkes. 2017. High altitude flights by ruddy shelduck (Tadorna ferruginea) during trans-Himalayan migrations. J Avian Biol In press:doi: [10.1111/jav.01443].

Powell F.L. 2007. The influence of chronic hypoxia upon chemoreception. Respir Physiol Neurobiol 157:154-161.

Powell F.L., H. Shams, S.C. Hempleman, and G.S. Mitchell. 2004. Breathing in thin air: acclimatization to altitude in ducks. Respir Physiol Neurobiol 144:225-235. 
1 Scott G.R. 2011. Elevated performance: the unique physiology of birds that fly at high altitudes. J Exp Biol 214:2455-2462.

3 Scott G.R., L.A. Hawkes, P.B. Frappell, P.J. Butler, C.M. Bishop, and W.K. Milsom. 2015. How $4 \quad$ bar-headed geese fly over the Himalayas. Physiology 30:107-115.

5 Scott G.R. and W.K. Milsom. 2007. Control of breathing and adaptation to high altitude in the 6 bar-headed goose. Am J Physiol Regul Integr Comp Physiol 293:R379-R391.

7 Scott G.R. and W.K. Milsom. 2009. Control of breathing in birds: implications for high altitude flight. pp. 429-448 in M.L. Glass and S.C. Wood, eds. Cardio-Respiratory Control in Vertebrates: Comparative and Evolutionary Aspects. Springer-Verlag, Berlin.

Shah N., H.B. Ragaswamy, K. Govindugari, and L. Estanol. 2012. Performance of three newgeneration pulse oximeters during motion and low perfusion in volunteers. J Clin Anesth 24:385-391.

Storz J.F. 2016. Hemoglobin-oxygen affinity in high-altitude vertebrates: is there evidence for an adaptive trend? J Exp Biol 219:3190-3203.

Swanson D.L. 2010. Seasonal metabolic variation in birds: functional and mechanistic correlates. pp. 75-129 in C.F. Thompson, ed. Curr. Ornithol. Springer New York, New York, NY.

Tucker V.A. 1967. Method for oxygen content and dissociation curves on microliter blood samples. J Appl Physiol 23:410-414.

Van Vliet B.N., J. McGuire, L. Chafe, A. Leonard, A. Joshi, and J.-P. Montani. 2006.

Phenotyping the level of blood pressure by telemetry in mice. Clin Exp Pharmacol Physiol 33:1007-1015.

Wu T. and B. Kayser. 2006. High altitude adaptation in Tibetans. High Alt Med Biol 7:193-208. 
1 Zur B., A. Hornung, J. Breuer, U. Doll, C. Bernhardt, M. Ludwig, and B. Stoffel-Wagner. 2008. A novel hemoglobin, Bonn, causes falsely decreased oxygen saturation measurements in pulse oximetry. Clin Chem 54:594-596. 


\section{Figure Legends}

Figure 1. Andean geese exhibit relatively modest physiological responses to acute hypoxia

exposure. Volume data are shown in units at standard temperature and pressure (STP). *

Significant pairwise differences between cannulated and uncannulated birds within each inspired $\mathrm{O}_{2}$ tension using Bonferroni post-tests in two-factor ANOVA.

Figure 2. There was strong similarity between the heart rates measured using the MouseOx

Plus ${ }^{\circledR}$ pulse oximetry system and those measured using electrocardiography (ECG) in individual uncannulated birds. Shown is a linear regression between methods (solid black line: $y=0.913 \mathrm{x}+$ $\left.12.37 ; \mathrm{R}^{2}=0.902 ; \mathrm{P}<0.001\right)$, in which solid grey lines represent $95 \%$ confidence intervals and the dotted grey line is the line of equality.

Figure 3. Arterial $\mathrm{O}_{2}$ saturation $\left(\mathrm{SaO}_{2}\right)$ measured in uncannulated birds using a MouseOx Plus ${ }^{\circledR}$ pulse oximetry system and in blood samples from cannulated birds. $(A) \mathrm{SaO}_{2}$ measurements were generally lower in cannulated birds compared to uncannulated birds, but the pairwise difference between groups was only significant at an inspired $\mathrm{O}_{2}$ tension of $7 \mathrm{kPa}(*$, as reflected by results of Bonferroni post-tests in two-factor ANOVA). $(B)$ Linear regression between methods for $\mathrm{SaO}_{2}$ data at each inspired $\mathrm{O}_{2}$ tension (solid black line: $\mathrm{y}=0.917 \mathrm{x}+14.3 ; \mathrm{R}^{2}=0.965 ; \mathrm{P}=0.003$ ), in which solid grey lines represent $95 \%$ confidence intervals and the dotted grey line is the line of equality.

Figure 4. The hypoxic ventilatory response of Andean geese is blunted relative to other species of waterfowl. Volume data are shown in units at body temperature and pressure (BTP), in order to provide a consistent comparison between our new Andean goose data reported here and our previously published data for bar-headed geese (a species that flies at high altitudes during its migration across the Himalayas), greylag geese, and Pekin ducks (both low-altitude species) (Scott and Milsom 2007). 

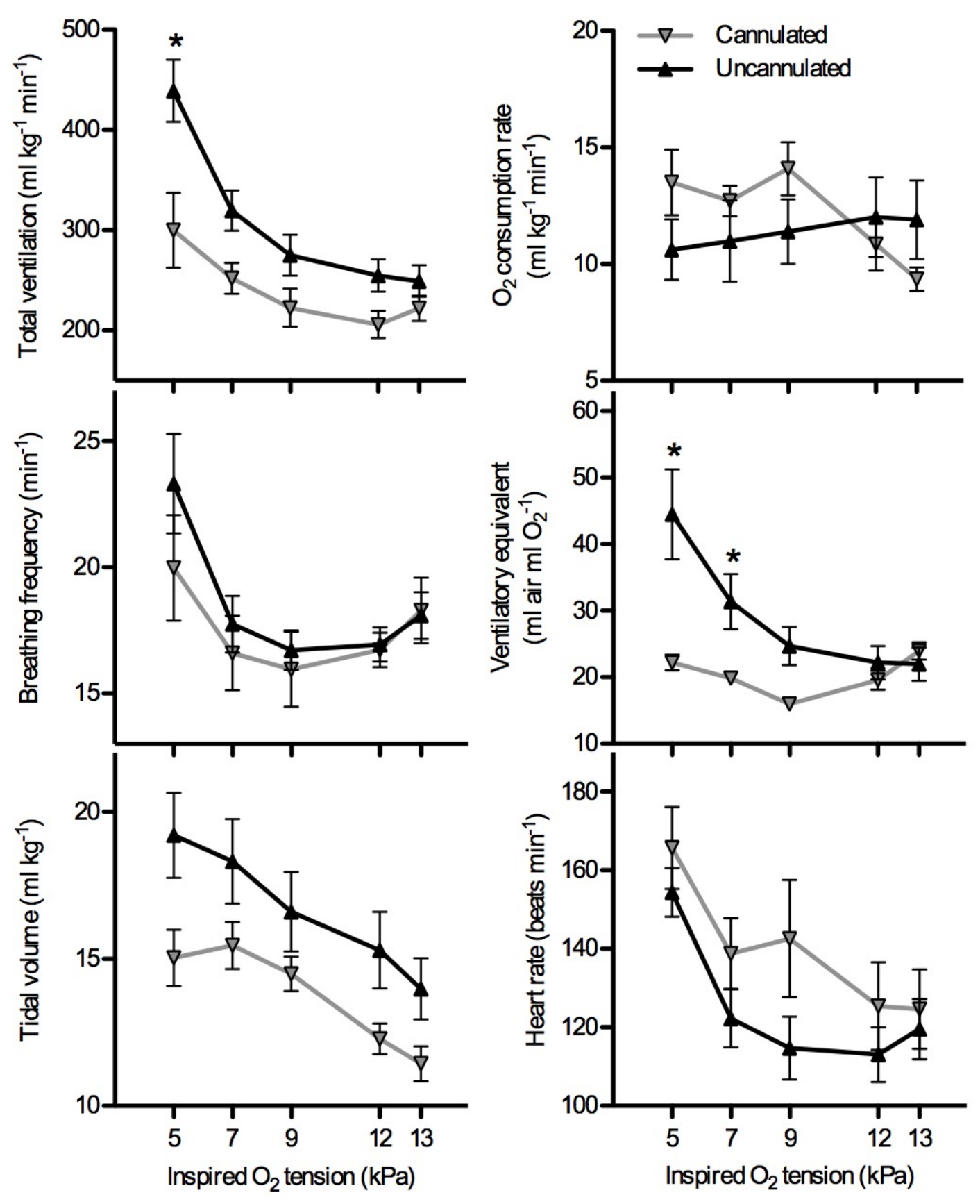


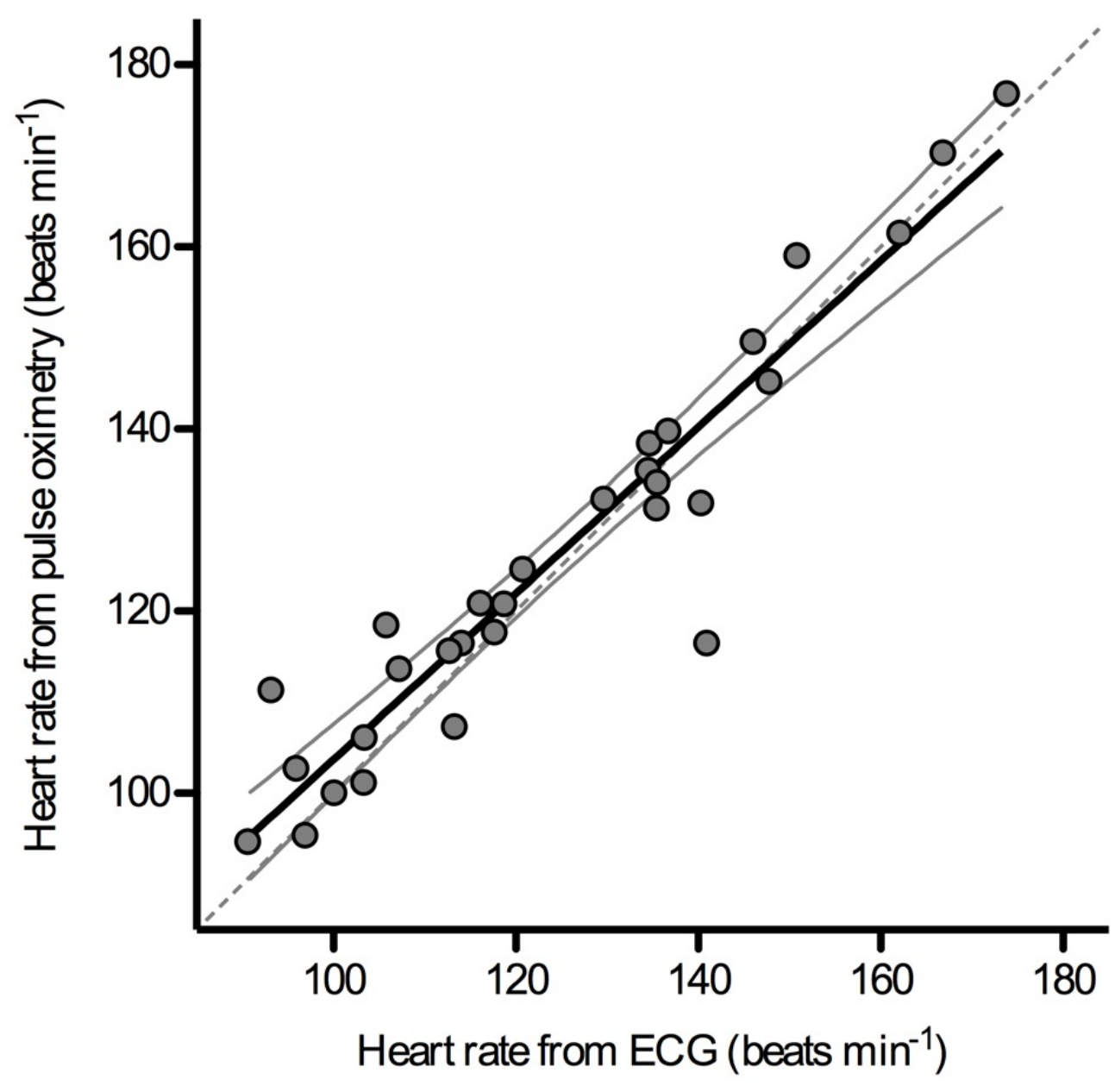

1 

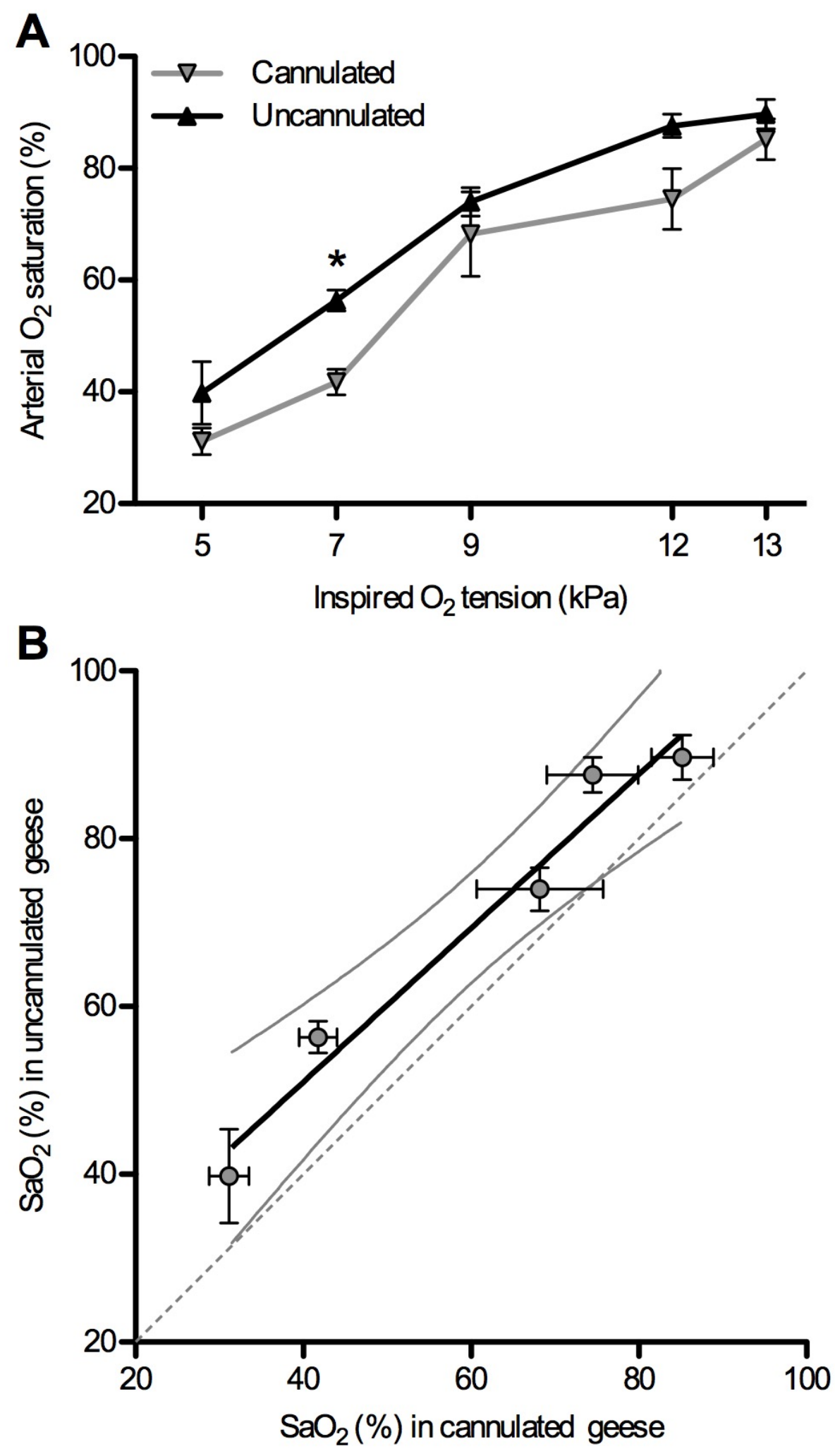


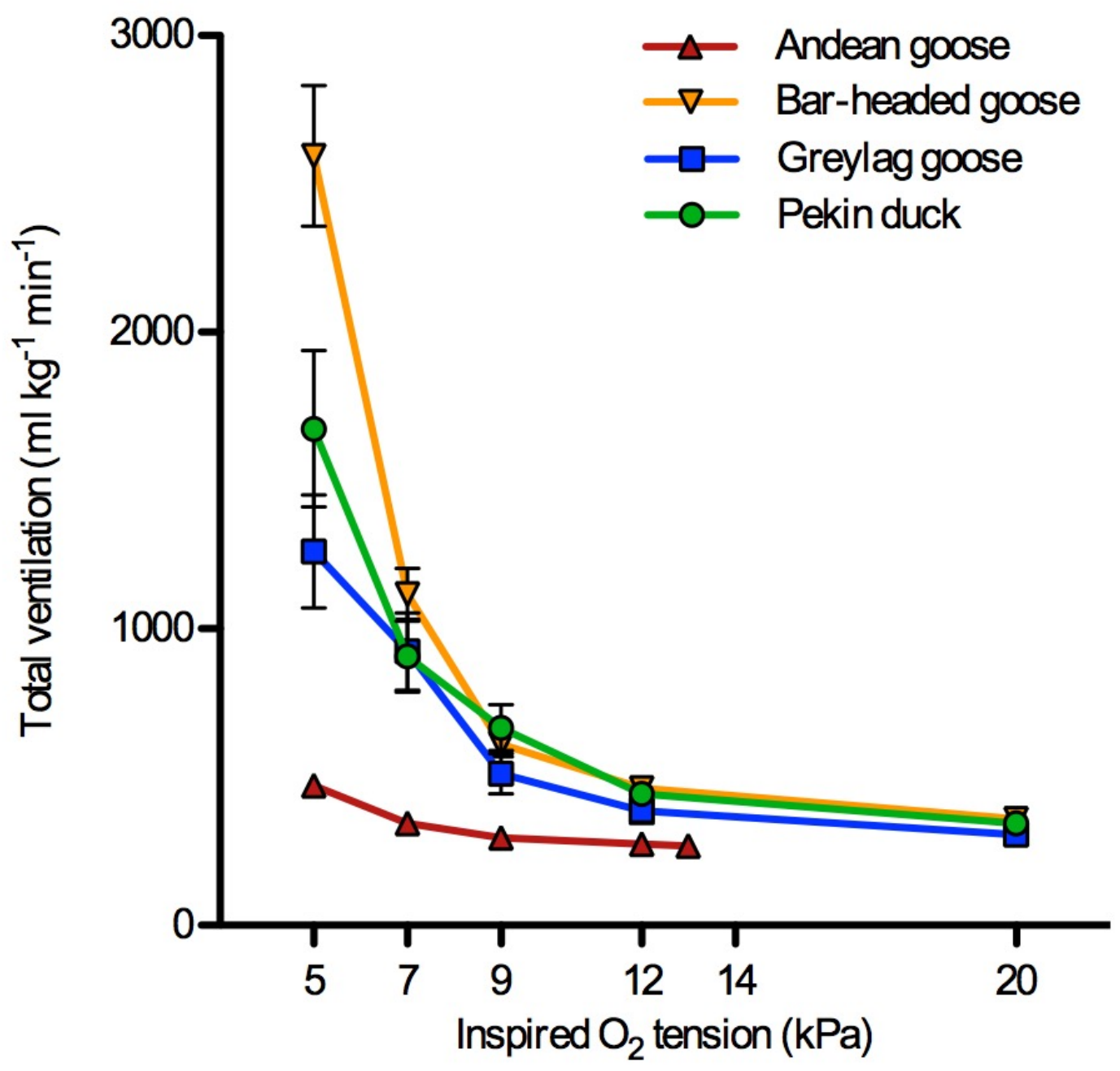

